\title{
Innovation Information Service of University Library Readers
}

\author{
Maoli Xu \\ Library \\ Jilin Agricultural University \\ Changchun,,China \\ 729738677@qq.com \\ +8615604305161
}

\begin{abstract}
In the digital, networked development environment, the needs of readers of the literature showing a wide range of information , integrated, efficient, on library services also put forward higher requirements. From the behavior of library users , diversity advisory services and personalized feedback service were discussed and proposed concrete measures to improve the quality of service of the reader .
\end{abstract}

Keywords- Information Age University Library ; Reader Service

\section{INTRODUCTION}

The rapid development and wider application of network technology, to promote the concept of the traditional library services , clients , service content, service features, services and service delivery means unprecedented changes occurred . Transformation and colorful network of information resources information services to further stimulate the demand for new library users awareness , demand generation features. Whether it is a traditional service or in a network environment, the user is always the main library services to user needs as the center of service is the only constant. Under the new features fully understand and study the information needs of the user network environment, new issues , in favor of ways to adjust and improve library and information services, improve service quality, to maximize the utilization of information resources .

\section{BEHAVIOR OF LIBRARY USERS}

Readers behavior refers the reader to use the library during the performance of a series of actions such as language , attitude , posture, manners and so on. Library Service combines practical activities , specifically to the hall can be divided into the behavior of the reader , the reader needs activity, the reader query behavior , readership habits analysis , the reader behavior evaluation.

\section{A. the behavior of the reader to Hall}

Readers museum acts mainly refers to services such as Readers, Reference and other activities through traditional readers reproduction readers to stay in the library traces can provide first-hand information for the readers of the library service quality ${ }^{[1]}$. For example the reader to the hall traffic , the number of readers per capita to the museum, the Museum of the frequency of the reader, the reader to the purpose hall , museum readers to stay in time.

\section{B. the reader needs activities}

Readers demand activity , also known as reader survey analysis. The main readership survey is to understand the needs of a particular aspect of the library , expand the highly targeted audience satisfaction questionnaire -type surveys, usually based on a certain understanding of the scope of the reader 's use of the library frequency region . Be collected basic data about the readership, and analysis. Detailed investigation covers the time, presented in a way, contact information, library type, age structure, educational structure, title structure, the structure of disciplines, such as consulting a question of library services, database use , and so satisfied with the attitude of librarians degree and the recommendations made to the library .

\section{C. the reader query behavior}

Readers query behavior refers the reader to classify, analyze query behavior for a certain class of readers [ 4 ] . For example Novelty can peep reader inquiry service characteristics $^{[2]}$. Novelty is the investigation of new stations provided by the client in accordance with the new investigation needs to verify its novelty science and technology content, in accordance with the relevant standard operation, and make conclusions. The task is to check for new research project , the results of identification , patent applications, technical consulting and other work support system , based on the content of their work is based on the literature, the use of search tools, retrieved through a comprehensive analysis of comparative literature, fairly and objectively circumstances described in the investigation of new projects, technology issued, provide reliable basis for literature research project, the results of identification , patent applications, technical consulting. Check the new role is to provide an objective basis for the research project for the scientific and technological achievements identification , evaluation, acceptance, transformation, incentives to provide an objective basis for research and development of scientific and technical personnel to provide a reliable and rich information, but also to provide an objective basis for behavioral studies reader .

\section{D. the reader evaluation}

Readers evaluated mainly in the field of information the reader feedback, evaluation body for readers , librarians can conduct self-assessment, inviting readers to participate in 
outside of the library service evaluation activities, ways to take the suggestion box , whispering gallery and so on. Specific resources covering construction , service, electronic resources, library website. Such as ease of use and usefulness of the library website is the issue of most concern readers $^{[3]}$. It is to study the availability of the interface library, is easy to use and to emphasize the use of a permanent

\section{THE DIVERSITY CONSULTING SERVICES}

Characteristics of the reader services can improve the quality of service, but the reader still borrow retrieval process will inevitably produce a variety of problems . Variety of consulting services for readers answering questions from multiple sources, to further improve service efficiency.

\section{A. An artificial Desk}

Human Services is one of the most traditional university library, the most effective way of consultation , the consultation process in the artificial librarian patient friendly service, as well as face to face communication and interaction readers can understand the needs and difficulties of readers to the maximum extent, readers can quickly and easily solve the problem . Artificial desk is an essential consulting services content, most of the university library is provided with the service.

\section{B. online consulting service}

With the development of communication technology, the reader may no longer need a special trip to the library to-face consultation , a number of easy-to- answer questions can be way more convenient online consultation, such as telephone , online chat tools. This online consultation service to and from the library readers can not only save time , but when the questions readers have their own issues and summarized, but also can improve service efficiency. In this regard, the library can configure the equipment and personnel in the labor desk to provide this type of service .

\section{C. microblogging and micro-channel consulting services}

Microblogging, micro-channel in recent years rapid development and popularization of network communication, widely used by the majority of the new generation of students . In order to adapt to the times and technological advances, the library is necessary on the basis of the online consultation, and further added Weibo micro-channel consulting services. This can only be from the perspective of diverse services, but the reader through the microblogging viewing content related issues are expected to solve their own problems, so as to reduce the problem of duplicate consulting services similar waste of resources ${ }^{[4]}$.

\section{D. the book describes}

To overcome this situation, the university library should be based on the several passive consultation, proactive consulting service book describes. Send information by publishing a new book book information on a web page or Twitter, to concerns related books readers e-mail , etc., so that readers can understand the message the museum to add books to the maximum extent, improve the efficiency in the use of books .

\section{PERSONALIZED FEEDBACK SERVICE}

Reader feedback is an important way to test the quality of service , improve service method. So , how to get from readers at more and more effective advice and feedback , is a key university library service work . Personalized feedback service is expected to improve the existing service deficiencies, improve the quality of related work. On this issue, we summarize the following points experience.

\section{A. Department summary}

Department summarize feedback is the starting point to work. University Library relevant departments should regularly aggregated reader comments and feedback information to develop interim solutions, and according to the characteristics of different audiences, times and improve their methods of work and service strategies.

\section{B. the follow-up survey}

Follow-up survey is an important part of the feedback service. By tracking surveys readers can understand the issue is reflected in the appropriate solution, whether the service improved method still insufficient . However, for the reader to implement personal opinion survey on personal preferences vulnerable to the impact of the reader , making the investigation is biased ; while for teachers and students of the investigation, it will spend a lot of manpower and resources, and may not be able to achieve the desired effect . Therefore, the reader how to implement follow-up survey is the main problem of the link . The combination of previous experience, we believe in the traditional method, combined with a rich network communication can be effectively tracked means. Specifically, you can open up in the university library homepage feedback column published real-time feedback from readers and museum services to make adjustments accordingly, and understand the effect of the improved service through messages and other means ${ }^{[5]}$. In addition, you can also carry out periodic public reports feedback problems and associated readers through face to face communication, to further improve the follow-up survey work .

\section{C. book reviews and scoring}

Among the feedback information, the current lack of book content feedback. In other words, what are the most popular books in the museum or classic books ; Which books of great help to the reader, is the " good book " ; What books outdated content, layout confusing, is the "second book" ; utilization compared to what books high , and so on , and books such information related to the actual content of lack of feedback, leading the reader when 
retrieving book information, only to get a book author, publisher , catalog sections and other basic information , but can not get the reader has read the book the evaluation , which can only be with the feeling from the books in several randomly selected. This would not only reduce the efficiency of books, but also enables borrow "second book" readers a waste of time, reducing their enthusiasm for reading books in the museum . Therefore, it is necessary to the creation of the University Library forum comments and scoring in each of the books online loan information . Evaluation by those who have read the feedback, the content of the book provides the general information for subsequent readers to help them determine whether they are useful to the books .

\section{CONCLUSION}

According to the characteristics of existing library services, I believe that it is necessary to provide the service characteristics of the reader , diversified consulting services, personalized feedback services to further improve the service quality of the librarian , improve existing service methods, improve library service system, to provide readers with a better service .

\section{REFERENCES}

[1] Fu Liqin . Library Services in the "people-oriented " [J], Library and Information Service, 2010 ( 11 ) : 50 - 53

[2] Guo Peimin. Library service standards "reader satisfaction" as the goal of Analysis [J], New Century Library , 2010 ( 6 ) : 51-53.

[3] Zheng Weibo, Tan Fangfu. College Library Service for teachers on how readers [J]. Library Work and Study , 2010 ( 10 ):105- 107.

[4] Wang Yujing. Based on university library information service user needs to explore [J]. Practice research , 2009 ( 11 ) :83- 85.

[5] Yuan Zeng, Leng Xiujin. Readers comparison and reference services at home and abroad [J]. Journal of Medical Library and Information Science , 2011 ( 6 ) : $10-12$. 